\title{
IMPACTS OF GRADIENT STRUCTURE ON THE DYNAMIC Characteristics of Machining Process System
}

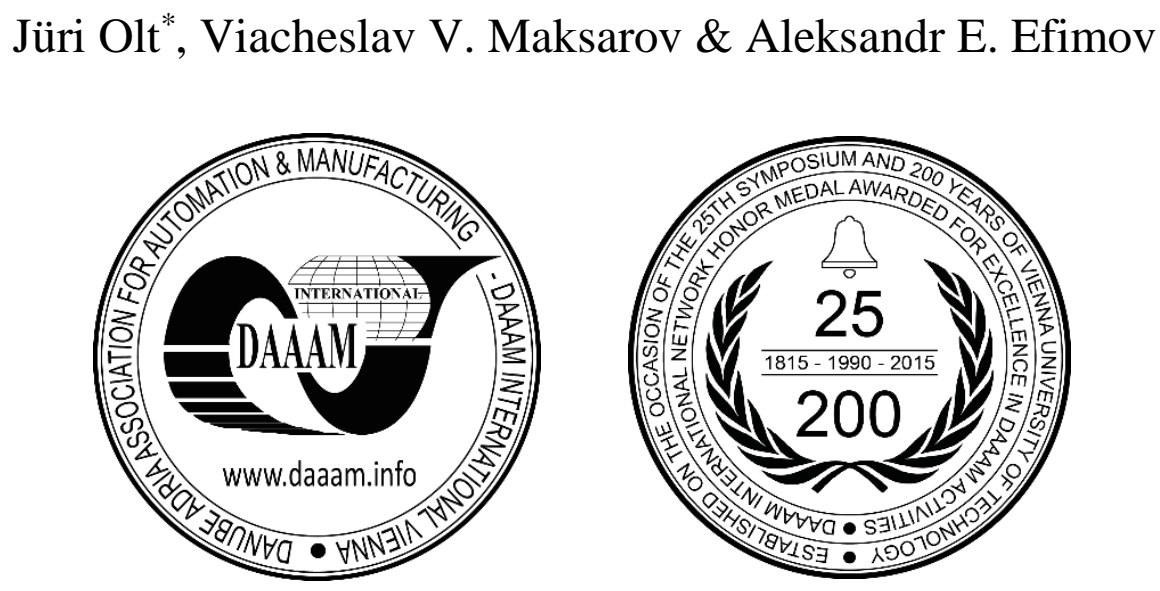

This Publication has to be referred as: Olt, J[ueri]; Maksarov, V[iacheslav] \& Efimov, A[leksandr] (2018). Impacts of Gradient Structure on the Dynamic Characteristics of Machining Process System, Proceedings of the 29th DAAAM International Symposium, pp.0190-0196, B. Katalinic (Ed.), Published by DAAAM International, ISBN 978-3-90273420-4, ISSN 1726-9679, Vienna, Austria

DOI: $10.2507 / 29$ th.daaam.proceedings.027

\begin{abstract}
The authors of this article identify the influence of a gradient structure on the dynamic characteristics of a production process system and surface roughness taking shape during machining. Such a task is due to the finishing operation used in most production processes. Embedment of abrasive particles into the surface layer of a workpiece is an irreversible effect of its charging by a grinding wheel. At the running-in stage, mating surfaces are severely worn because of abrasive micro particles, deteriorating performance properties of parts. In this regard, we have proposed a new approach to achieving specified surface quality based on auto-oscillation process suppression during machining by combined destruction of gradient structure in a local chip formation region. It was established that using this method reduces auto-oscillation amplitudes, and therefore improves $R_{a}$ surface roughness parameter value 1.65 times. This allows to exclude the grinding operation from manufacturing process when the specified quality parameters are reached.
\end{abstract}

Keywords: local laser effect; gradient structure; chip formation; surface roughness

\section{Introduction}

Present-day engineering products operation practice demonstrates that in $80 \%$ of cases, disruption of natural functioning of mating parts is due to the process of severe wear of their contacting surfaces. The principal cause of deterioration in friction pairs wear resistance is poor surface preparation at the production process stage [9].

The primary point of issue is circular grinding operation the process whereof was accompanied by an irreversible charging effect. From the physical point of view, this phenomenon is essentially embedment of abrasive micro particles from the grinding wheel into the workpiece surface layer. The surface of a part prepared using such a process functions as a abrasive cloth causing severe wear of rubbing contact pairs and bringing about a reliability and performance deterioration during operation. For which reason, it is proposed to replace a finishing operation and to improve the micro geometrical parameters brought about by the production process during machining [1].

Thus, as we consider the surface micro relief as an object of study, roughness characteristics are brought to the fore. Such process factors as machining conditions; geometrical parameters and the quality of the active part of a cutting tool; temperature influence; elastic plastic deformations of the layer being removed; machining process system (MPS) vibrations [2], [7], [8], [12]. 
To a greater extent, roughness is sensitive to changing MPS dynamic characteristics, i.e. amplitude and frequency. Their presence in an isolated system is due to the motion of material bodies 'tool-part' contacting each other. This motion arises as a result of application of variable external cutting forces because of an impact of elastic plastic deformation of the excess metal being removed. The conditions under which vibrations are excited in a process system are due to alternate delay of the cutting and friction forces being in a complex association with the chip formation process. For this reason, transiency arises in the variability of both kinds of forces because of an elastic force pressing the tool away from the workpiece, bringing about oscillation of the MPS and the emergence of an auto-oscillation process. The fact that the occurrence of self-excited oscillatory processes in a closed system brings about deterioration of workpiece roughness is generally known [1], [6]. Therefore, solving the problem of vibration suppression in a MPS is an important research mission.

\section{Materials and Methods}

One can consider high-energy local laser effect (LLE) as a promising and progressing method of auto-oscillatory process amplitude suppression [10], [11]. This method is divided into several consequent stages. The first one concerns the issues of laser irradiation interaction with the workpiece metal surfaces. The second one is the process of machining a workpiece with a preliminarily altered local structure itself. For the sake of clarity, we shall consider the stages described above in more detail.

The laser effect method is basically heating a local workpiece area above the phase transition points of the iron-carbon diagram $A_{c l} \rightarrow A_{c 3}$ up to the $T_{S} \rightarrow T_{L}$ values (Fig. 1) [5]. Two important points deserving attention should be considered in this high temperature range.

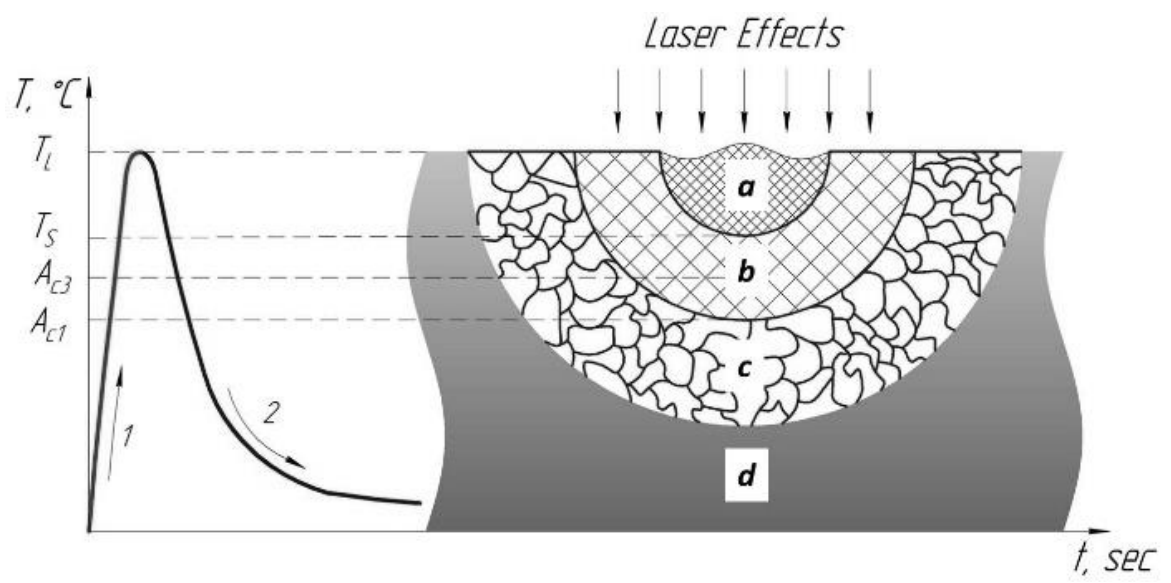

Fig. 1. Gradient structure after a LLE where 1 is heating, 2 is cooling, $a$ is the surface melting zone, $b$ is the hardened zone, $c$ is the transition zone, $d$ is main layer of metal.

They are polymorphic transformations of metal involving changes in crystal lattice type and thermal distortion. That latter process is due to the fact that a local area of metal is being heated and this area undergoes structural changes accompanied with an increase or decrease in volume [3], [4].

On the other hand, beyond the borders of the laser-heated spot metal retains its ordinary state, i.e. it is not affected by laser effect, and therefore, it is a barrier for expansion of the volume of newly formed structures in the local zone. This will entail elastic, and then plastic deformation and upon cooling down a gradient structure having enhanced residual stresses will be formed. As a result, the LLE process comes down to creating a structure that would have different physical and mechanical properties from the base metal.

Since this article considers the task of improving the surface roughness of a workpiece made of medium carbon steel 45 and alloy steel $40 \mathrm{Cr}$, all subsequent studies will be carried out using the abovementioned classes of metals.

A Ls-5 ytterbium fiber laser station operating in a continuous emission mode was used to create a local gradient structure in the workpiece surface layer. Experimental studies aimed at microstructure detection and mechanical properties determination after laser irradiation of 45 and $40 \mathrm{Cr}$ grades steel were carried out using micro sections having an area of $1 \mathrm{~cm}^{2}$, etched in an alcohol solution $(100 \mathrm{~mL})$ of nitric acid $(4 \mathrm{~mL})$. Changes connected with structural transformations in the local zone of the samples (Fig. 2) were monitored using a Leica DM2500 M microscope, and mechanical properties were studied with the help of a PMT-3 micro hardness tester under load H $\mu 50 \mathrm{gm}$. The structural layers that took shape are designated in accordance with Fig. 1.

The experiment performed by us has demonstrated that needle-shaped marten site structure takes shape in the $b$ area during laser energy deposition of 45 grade steel (Fig. 3). Tempered zone $c$ consisting of a troostite-ferrite structure develops deeper in the metal, a ferrite network is formed closer to the border with original metal $d$. 

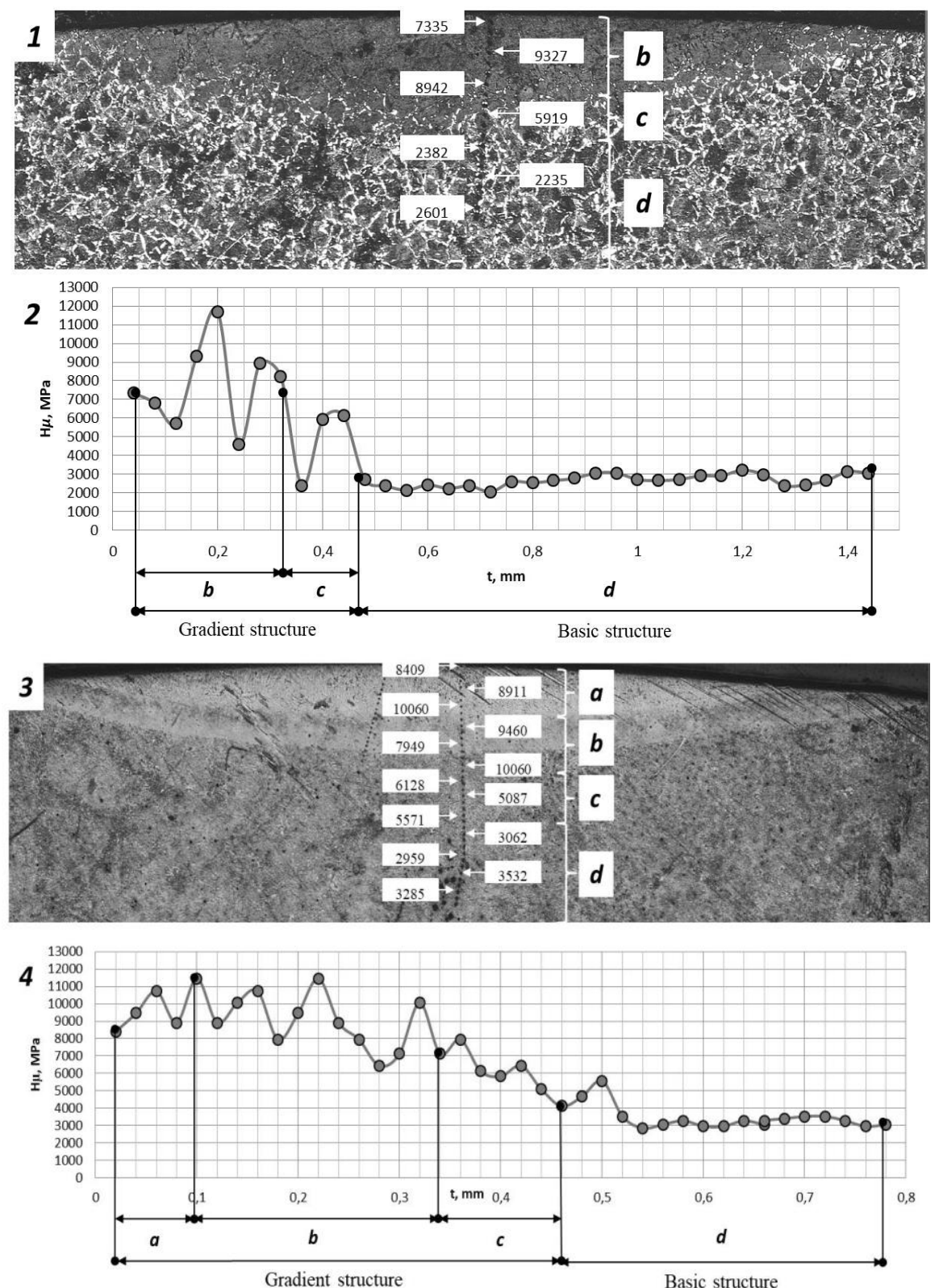

Fig. 2. Gradient structure (x25) in 45 (1) and 40Cr (3) grades steel with mechanical properties (micro hardness) unevenly distributed in depth $(2,4)$.
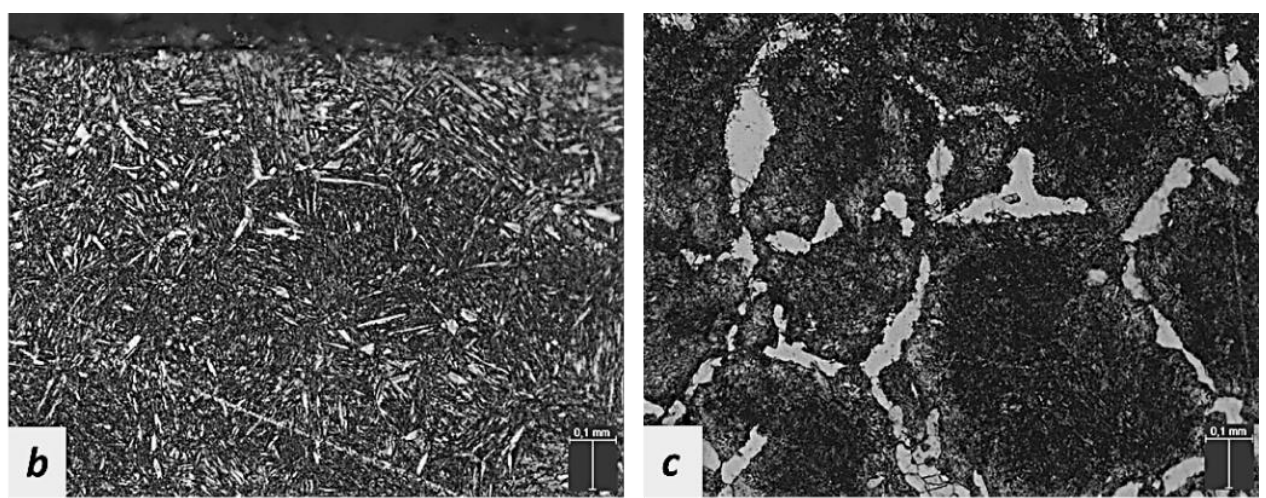

Fig. 3. Magnified microstructure of 45 grade steel (x50) areas after laser treatment under the following conditions: $P=2,100 \mathrm{~W} ; V=2,000 \mathrm{~mm} \mathrm{~min}^{-1} ; d_{s}=4 \mathrm{~mm}$. 
Subsequent metallographic analysis of 40Cr grade steel (Fig. 4) that had been subjected to laser effect showed that its microstructure was different from that of 45 grade steel. E.g., surface melting takes place at the top of $a$; it is characterized by a high heating temperature and a cooling rate about $10^{3}-10^{6} \mathrm{~K} / \mathrm{s}$, resulting in coring. Solid phase area $b$ adjacent to the melted zone border has a marten site structure. The closer to the tempered zone, the more carbides are split off, both inside the metal crystals and at their borders. A dispersed sorbet structure is formed in the zone of low temperature influences characteristic of area $c$.
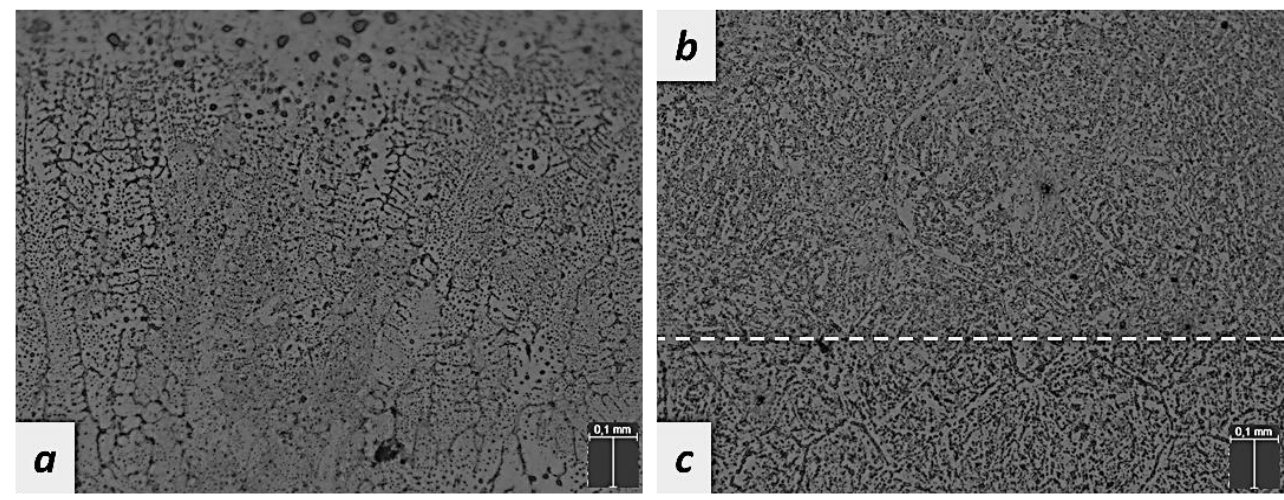

Fig. 4. Magnified microstructure of 40Cr grade steel (x50) areas after laser treatment under the following conditions: $P=2,200 \mathrm{~W} ; V=2,000 \mathrm{~mm} \mathrm{~min}^{-1} ; d_{s}=4 \mathrm{~mm}$.

During machining, such a set of structural zones that are different in structure and have different mechanical properties will develop cracks and subsequently fracture under the impact of applied external cutting forces. Theoretically, the process of origination, development and fracture of chips in the gradient structure area can be described as follows (Fig. 5).

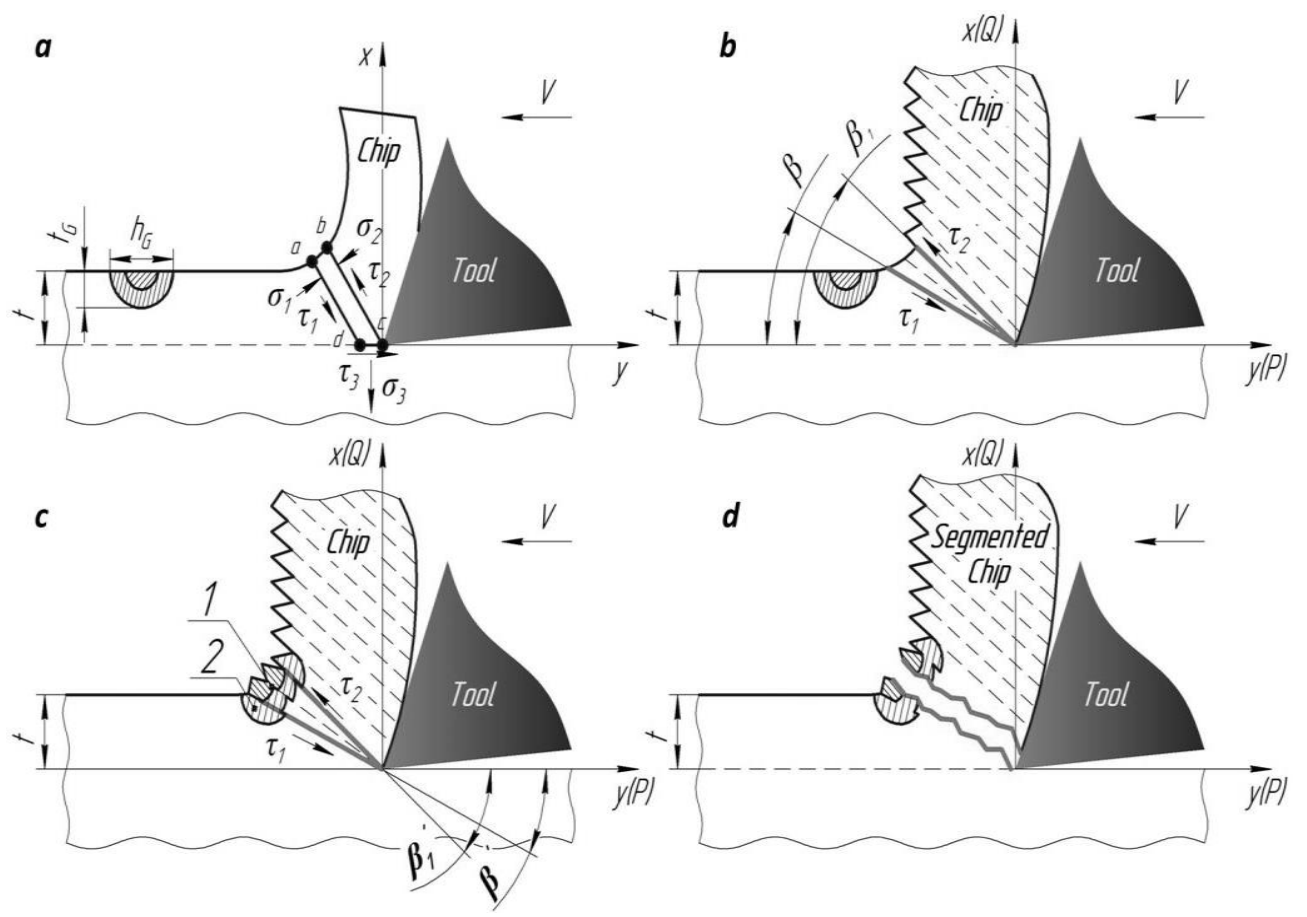

Fig. 5. Conventional diagram of chip formation and fracture in the gradient structure region where: $\beta, \beta_{1}, \beta^{\prime}, \beta_{1}^{\prime}$ are localized shear planes; $V$ is cutting speed direction; $Q$ is friction force; $P$ is cutting force; $\sigma_{1}$ and $\sigma_{2}$ are normal compression stresses; $\tau_{1}, \tau_{2}, \tau_{3}$ are tangent stresses; $\sigma_{3}$ are tensile stresses; $h_{G}$ and $t_{G}$ are the LLE penetration width and depth.

A cutting tool plastically deforms the removed metal layer under the action of the force $P$, resulting in chips formation. Let us imagine that elementary layers $a, b, c, d$ adjoin the tool tip and are affected by normal stresses $\sigma_{1}, \sigma_{2}$ and tangent stresses $\tau_{1}, \tau_{2}$, while tensile stresses $\sigma_{3}$ and tangent stresses $\tau_{3}$ are observed in segment $d, c$ (Fig. 5, a) [2] and [8]. The next phase of the tool advance in the direction $O Y$ causes an instantaneous increase of stresses $\tau_{3}$ quickly achieving the breakdown point, forming a crack at the $d, c$ segment. Crack growth engender new surfaces free from previously applied stresses $\tau_{3}$ and $\sigma_{3}$. 
As a result, conditions are created for accelerated deformation of the $a, b, c, d$ layer along the primary shear border $\beta$ and the conventional shear border $\beta_{1}$ (Fig. 5, b), engendering friction forces $Q$ along the front surface of the tool. In this situation, compressing stresses $\sigma_{1}, \sigma_{2}$ virtually do not make any impact on the deformation layer, while the tangent ones $\tau_{l}$ и $\tau_{2}$ remain predominant, giving the chips a sawtooth configuration. As the gradient structure encounters the localized zones $\beta$ and $\beta_{1}$, the first stress spots are formed under the impact of shear deformations. Excess of the breakdown point in modified structures 1 (brittle) and 2 (quasi-brittle) (Fig. 5, c) under the impact of distortion of angles $\beta, \beta_{1}$ into $\beta^{\prime}, \beta_{l}^{\prime}$, will cause instantaneous initiation of a crack in them and its subsequent propagation into the metal depth. This will bring about a final fracture and separation of a chip from the surface being machined (Fig. 5, d).

In substantiation of the above theory presuming absence of cutting tool impacts against hard metal layers at the stage of machining, samples of chips were made (Fig. 6). The borders of the gradient structures are visible well; they prove that the cutter passes under a modified zone and the process of fracture is a consequence of elastic and plastic deformations.

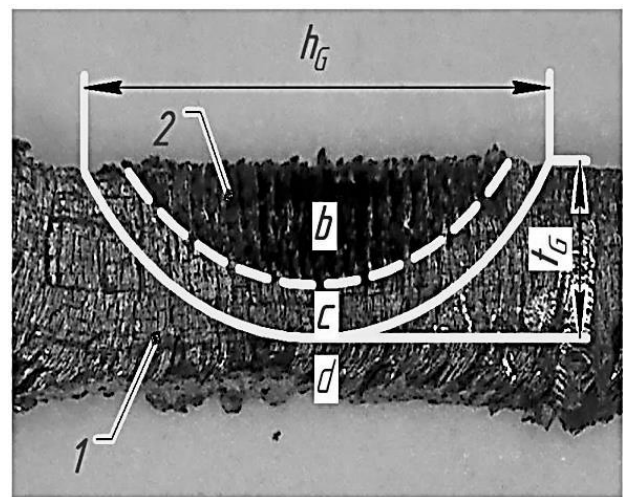

45 grade steel

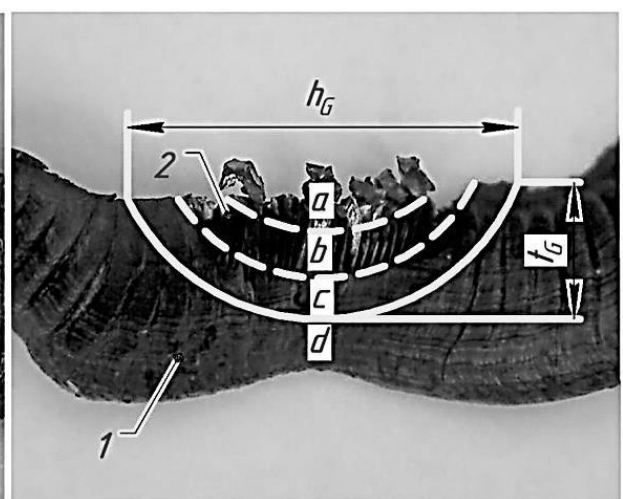

40Cr grade steel

Fig. 6. Samples of chips (1) with gradient structure regions marked out (2).

\section{Results and Discussion}

Our dynamic studies of the process of machining of a workpiece with a gradient structure (Fig. 7) on an EMCO Concept TURN 250 CNC lathe allowed us to established that the layers that have taken shape react to the fracture process flow in different manners, manifesting themselves distinctly at the chip fracture surfaces (Fig. 8). This confirms the fact that fracture takes place in a combined manner, with the participation of the fragile and the viscous mechanism. As we synchronize the obtained segmented elements of a continuous chips and the turning process oscillography chart as exemplified by $40 \mathrm{Cr}$ grade steel, we can establish the following consistencies.

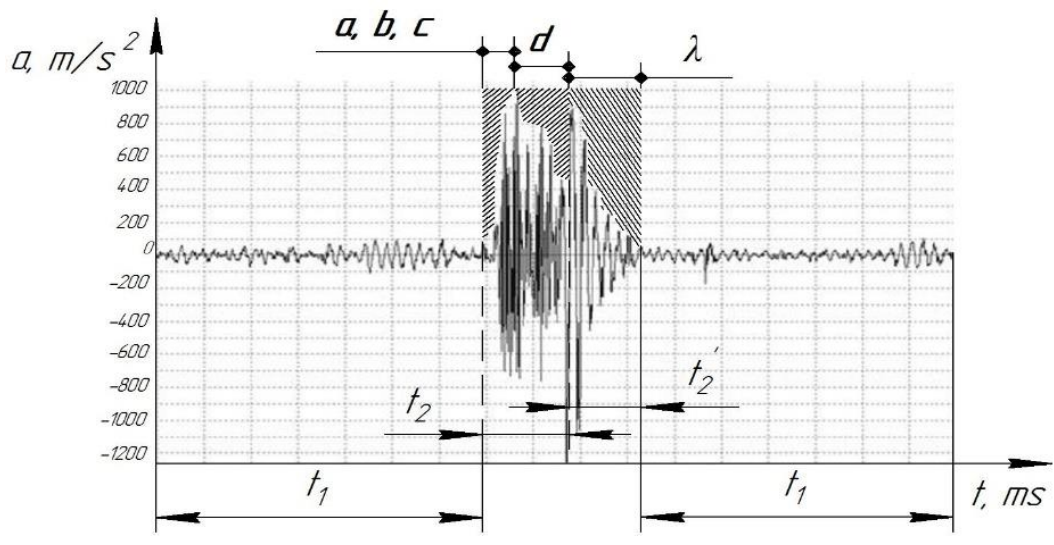

Fig. 7. Oscillography record of 40Cr grade steel machining process where: $t_{1}$ is the area of ordinary machining; $t_{2}$ is machining in a region with a gradient structure; $t_{2}{ }^{\prime}$ is natural oscillations range; $\lambda$ is logarithmic attenuation decrement. Machining conditions: $V=100 \mathrm{~m} \mathrm{~min}^{-1} ; S=0.15 \mathrm{~mm} \mathrm{rev}^{-1} ; t=0.8 \mathrm{~mm} ; h_{G}=5.5 \mathrm{~mm} ; t_{G}=0.45 \mathrm{~mm}$.

As described above, a after laser treatment a metal workpiece made of $40 \mathrm{Cr}$ grade steel undergoes a martensitic transformation in the $a$ and $b$ zones, while a tempering structure dominates at the $c$ area. A mechanism of instantaneous fragile fracture is characteristics of such structures; this is confirmed by shining surfaces visible on the samples (Fig. 8, zones a, b, c). Therefore, at the initial moment of time $t_{2}$ (Fig. 7, vibration record segments a, b, c) the process system movement accelerates until the crack encounters the original structure $d$.

Having contacted the plastic structure $\mathrm{F}_{\mathrm{P}}+\mathrm{P}$ subjected to a viscous fracture mechanism (the matt surface dissipating light rays is marked as the $d$ zone, Figs. 7-8), a developing crack slows down its advance. 
Further crack development brings about a complete rapture and separation of a chip segment from the surface being machined. This effect forces the MPS to disintegrate for 5-10 ms and to carry out oscillations that manifest themselves as logarithmic decrement $\lambda$ on the $t$, area, thus dissipating the amplitude of self-oscillations for that period of time.

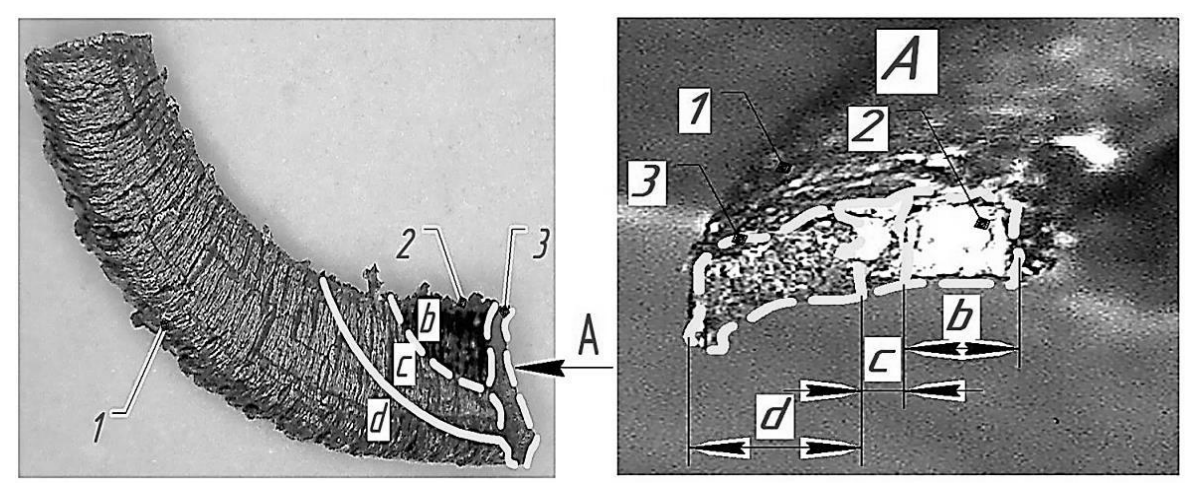

45 grade steel
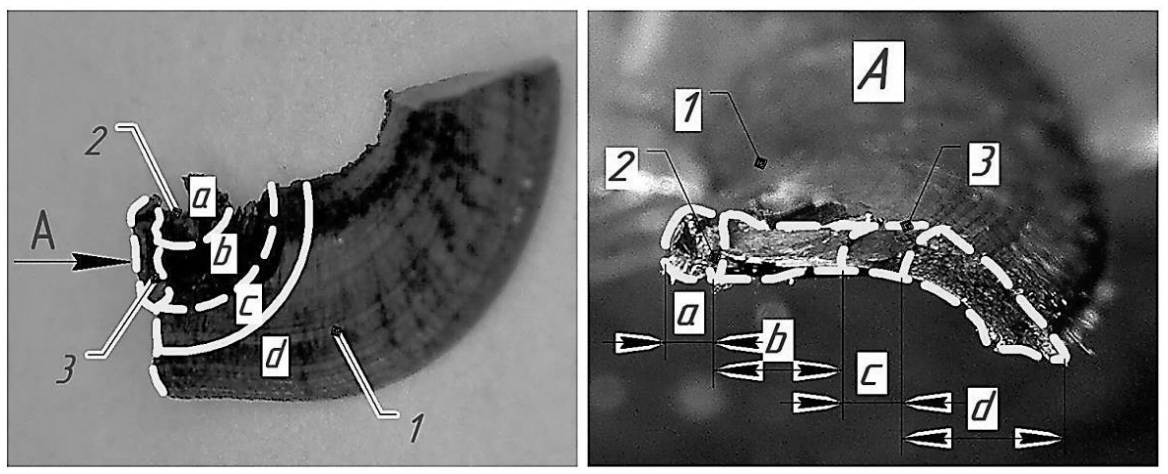

40Cr grade steel

Fig. 8. Segmented elements of continuous chips (1) obtained during machining of steel having a local gradient structure (2) with borders along which the combined fracture took place (3).

Building on the theoretical and experimental studies described above, it is necessary to assess the influence of selfoscillation process amplitude level on the surface roughness taking shape during machining of a steel workpiece with a gradient structure. MPS vibrations were measured using a Prüftechnik MT GmbH vibration diagnostic unit and surface roughness was assessed with the help of a SJ-210 instrument. The results of the studies are presented in graphic form in Fig. 9.

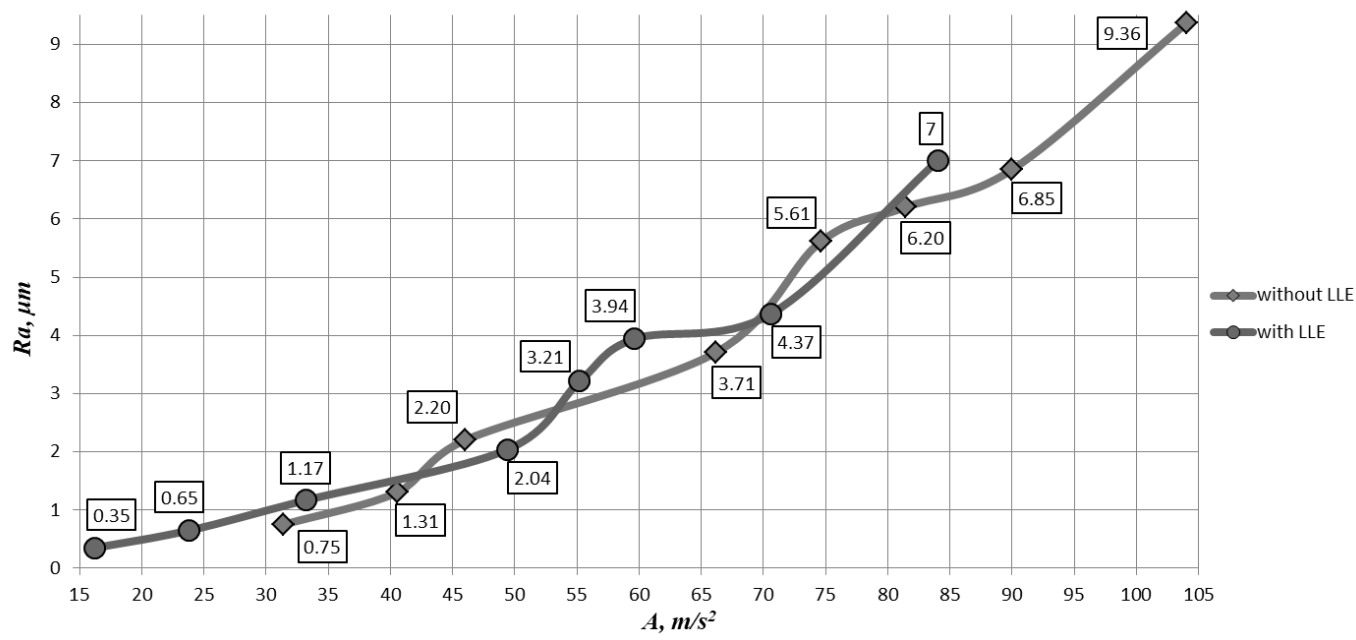

Fig. 9. Influence of self-oscillation process amplitude $A$ on surface roughness $R_{a}$ during machining of a workpiece with a gradient structure. 


\section{Conclusions}

The occurrence of self-excited oscillatory processes in a closed mechanical system results in workpiece roughness deterioration. Suppressing unwanted vibrations is very important in machining operations. In this paper the influence of the gradient structure on the dynamic characteristics of a production process system and producing surface roughness during machining is identified.

Summarizing the analysis of the above characteristic curve (Fig. 9), it is possible to state with complete confidence that the process of combined fracture of gradient structure in the region where a chip takes shape affects the self-oscillation amplitude favorably. This, in its turn, allows to improve the $R_{a}$ parameter of surface roughness 1.65 times at the machining stage of the production process and to forgo final grinding.

Future research plans are aimed at improving the workpiece surface quality during a final mechanical machining operation.

\section{References}

[1] Efimov, A., Maksarov, V. \& Vjushin, R. (2017). Technological control of surface layer roughness on the basis of modeling of transients. Metalworking, Vol. 2, pp. 39-45. (in Russian).

[2] Elyasberg, M.E. (1993). Self - Excited Machine - Tool Chatter. Theory and practice, St. Petersburg, OKBS, 180 pp. (in Russian).

[3] Grigoriants, A.G., Shiganov, I.N. \& Misjurs, A.I. (2006). Technological processes of laser processing. Tutorial, Moscow, MSTU named after N.E. Bauman, 664 pp. (in Russian).

[4] Grigoriants, A.G. (1989). Fundamentals of laser processing of materials. Moscow, Mechanical Engineering, 304 pp. (in Russian).

[5] Gulyaev, A.P. 1986. Metallurgy. Moscow, 544 pp. (in Russian).

[6] Khalimonenko, A., Maksarov, V. \& Olt, J. (2017). Managing the process of machining on machines on the basis of dynamic modelling for a technological system. Építőanyag - Journal of Silicate Based and Composite Materials, Vol. 69, No 2, pp. 66-71, DOI: 10.14382/epitoanyag-jsbcm.2017.12.

[7] Madissoo, M., Maksarov, V., Arak, M., Olt, J. (2012) Dynamic Modeling of the Cutting Process, Chapter 18 in DAAAM International Annals \& Proceeding 2012, pp. 213-224, B. Katalnic (Ed.), Published by DAAAM International, ISBN 978-3-901509-86-5, ISSN 1726-9679, Vienna, Austria, DOI: 10.2507/daaam.scibook.2012.18.

[8] Maksarov, V. (2015). Improving the accuracy of manufacturing of hydraulic power cylinders using vibration-proof cutting tool. Agronomy Research, Vol. 13, No 3, pp. 671-679.

[9] Maksarov, V. \& Krasnyi, V. (2017). The formation of surface roughness of piston rings or the purpose of improving the adhesion of wear-resistant coatings. Key Engineering Materials, Vol. 27, pp. 73-78, ISSN: 10139826, DOI: 10.4028/www.scientific.net/KEM.736.73.

[10] Maksarov, V. \& Olt, J. (2015). Development of chatter-resistant system of Cutting tool. Annals of DAAAM and Proceedings of the International DAAAM Symposium. 26th DAAAM International Symposium on Intelligent Manufacturing and Automation, DAAAM 2015; University of ZadarZadar; Croatia; 21 October 2015 through 24 October 2015; Code 123540, pp. 223-228; B. Katalinic (Ed.), Published by DAAAM International, ISBN 978-3902734-07-5, ISSN 1726-9679, Vienna, Austria, DOI: 10.2507/26th.daaam.proceedings.031.

[11] Olt, J., Liyvapuu, A., Madissoo, M. \& Maksarov, V. (2016). Dynamic simulation of chip formation in the process of cutting. International Journal of Materials and Product Technology, Vol. 1, Issue 53, pp. 1-14, ISSN: 02691900, DOI: 10.1504/IJMPT.2016.076363.

[12] Weitz, W.L. \& Maksarov, V.V. (2000). Dynamics and control of process of chip formation with cutting edge machining. Monograph, St. Petersburg, SZPI, 160 pp. (in Russian). 